\section{Ambiguous figures by Bosch}

\section{W. KROY and J. LANGERHOLC Messerschmitt-Bölkow-Blohm GmbH, Ottobrunn/Munich, West Germany}

Remarking on the paucity of material available for experimental studies of figure-ground reversal, Fischer (1967) points out that "artists, in advance of psychologists, appreciated that changes in the figural features of spatial forms may be induced by suitable juxtapositions of two-dimensional patterns" (p. 328). He mentions Bonnard, Vuillard, and Beardsley along with Dali and Escher, who seemed to have been so obsessed by this phenomenon as to have gone into mass production. Key (1980) has already called attention to subliminal effects in the works of Heironymus Bosch as antedating the latest modern school by about 500 years. In this short note, we wish to point out that Bosch used interlocking animal forms as well, albeit in so infinitely more subtle a fashion that they have gone largely unnoticed, or at least uncommented upon, in the literature of art criticism. Whether the later artists had, in fact, noticed this, were taught it as a "trick of the trade," or rediscovered it independently is left for others to debate.

\section{The Owl's Nest}

The work in question is the line sketch by Bosch (ca. 1500), reproduced in Figure 1, entitled The Owl's Nest. At first glance, the drawing appears simply to represent an owl alighting on a tree, onto which perhaps two other birds are clinging at the lower left. A closer inspection of this section of the picture reveals a number of other birds concealed to a greater or lesser extent in the picture. One of the less obvious, yet clearly noticeable, examples is to be found between the two conspicuous birds at the lower left. It is the outline of a bird's head (see Figure 2) formed by: (1) the trunk of the tree in the foreground, (2) a branch that might be from the same trunk or from another tree occluded by it, (3) a dotted line apparently intended to represent a secondary branch emanating from (3), and (4) an eye to top it off. This is the classic example of figureground reversal, in which the tree and its branches can appear as contours or background occluded by the head of the bird. What makes it all the less likely to have been an accident is the eye, which the reader could easily explain away in analogy with the other spiders, all too clearly hanging from invisible threads

The authors' mailing address is: Messerschmitt-Bölkow-Blohm GmbH AE33, Unternehmensbereich Apparate, Postfach 801149 , 8000 München 80 , West Germany. elsewhere. Yet its exact placement, which reinforces the other unlikely stroke (3) to form the primal sketch of a bird's head, indicates more than mere coincidence. One reinforcing coincidence is that the most prominent spider can also be considered as the eye of a rather large streamlined creature with a long bill/snout (Figure 2). The perceptual alternation between bird and tree is similar to the famous Rubin face-vs.-vase figures.

Quite a few other birds can be easily imagined as well (Figure 2), although it cannot be proved that they were placed there on purpose. The fact that they are more apparent on a photocopy than in the original does not, in our opinion, so much speak against Bosch's intent or awareness of this effect as for his intuitive realization that certain processors of nonfoveal resolution would be excited by them.

\section{The Rabbiduck}

Just above this imaginary bird's head is a black figure which appears to be another bird in the shadow of the trunk, a fair duplicate of the first bird turned right side up and foraging in the trunk. A closer look shows this figure to be ambiguous as well; reversing head and tail ends produces the equally likely bird hypothesis shown in Figure 3a. This is a case of a figure bivalent in itself, such as the celebrated Rabbiduck of Figure 3b. Here the ambiguity is not between figure and ground, but between two perceptual hypotheses as to what one and the same figure actually represents. The bivalence of the figure in question is enhanced by the bright spot on the gnarl of the branch extending the bird's tail, which may be construed as the eye of a bird in the reversed position.

\section{Human Anatomy}

It is not only birds that are represented much more heavily than one would have noticed at first glance; the tree trunk, when turned upside down, can be seen to decompose into two sections, both modeled on the male human body (Figure 4). At the left, in inversion, we find a man with spread legs, a beard, a fairly prominent nose, and a turban. The remaining main part of the trunk in outline (Figure 5) appears to be a sketch of a thigh taken directly from an anatomy class, the blackened part strongly suggestive of the male sex.

As a final example of hidden anatomical features, we mention the network of lines representing the tree's bark, in which a pair of hands clasped about the black hole in the trunk can be recognized. The hole itself, in which the owl has presumably made its nest, bears a striking resemblance to an enormous black bird's head with only the upper half of the beak showing. 


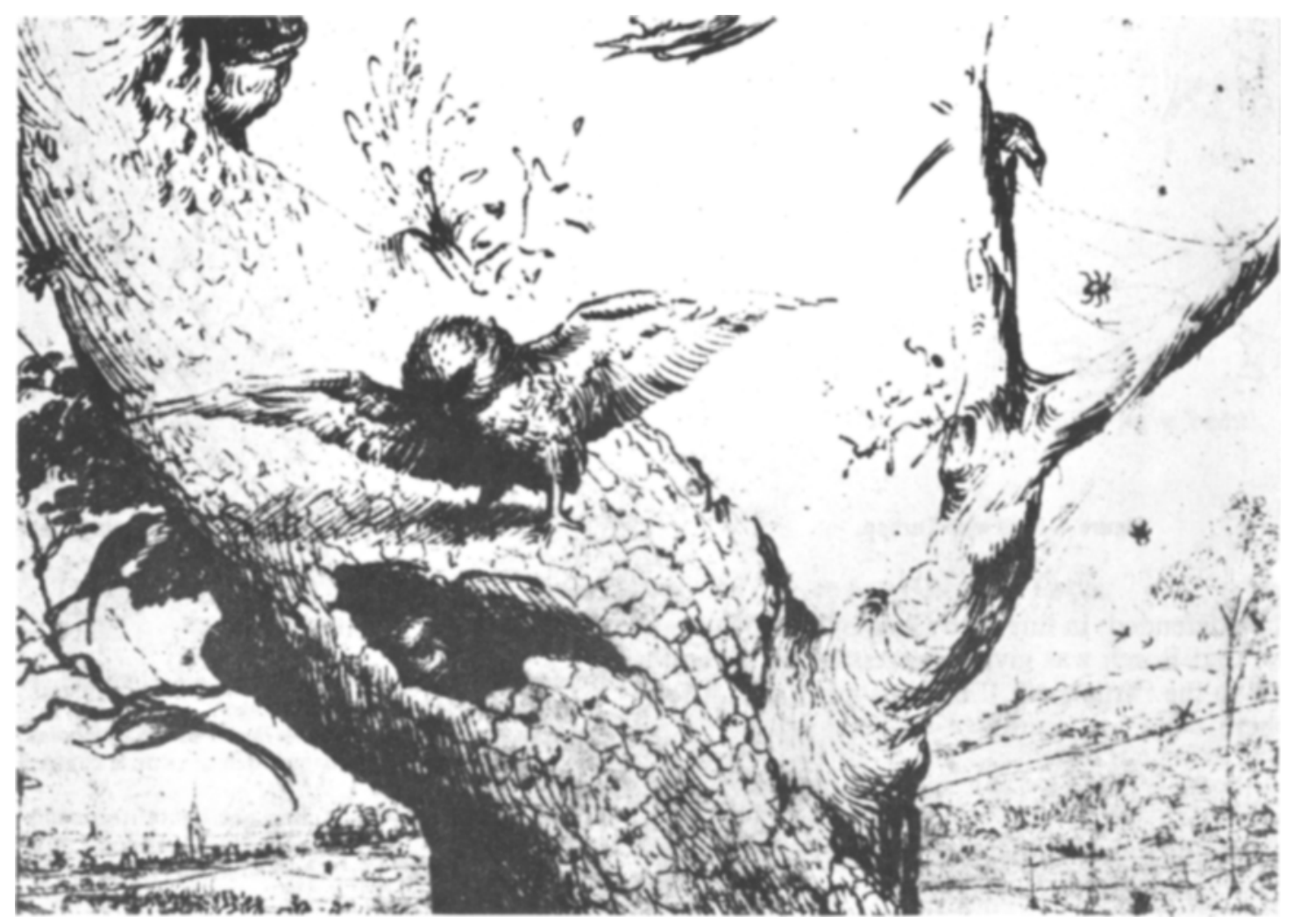

Figure 1. "The Owl's Nest," drawing by Hieronymus Bosch (ca. 1500; Museum Boymans - van Beuningen, Rotterdam, The Netherlands).

\section{Conclusions}

The variety and density of hidden figures in this picture, as well as their skilled execution, indicate that this is not a product of the artist's "unconscious," but rather that the figures were intentionally built into the drawing, either to enhance its intrigue or to tell a story, or both. ' One of the authors (J.L.) imagines that quite a few allusions to the book of Job

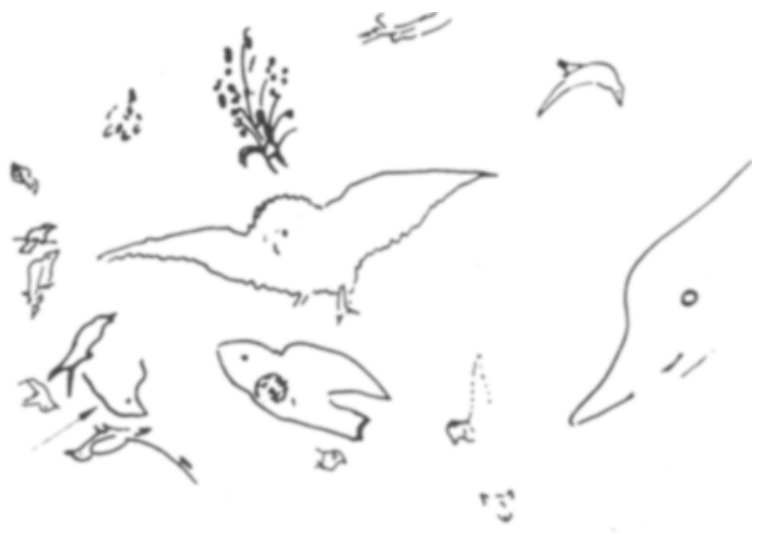

Figure 2. Outline of a bird's head formed by branches and trunk. (a)

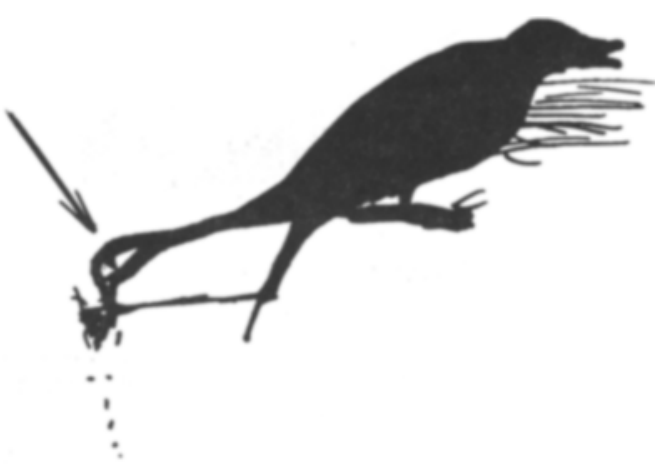

(b)

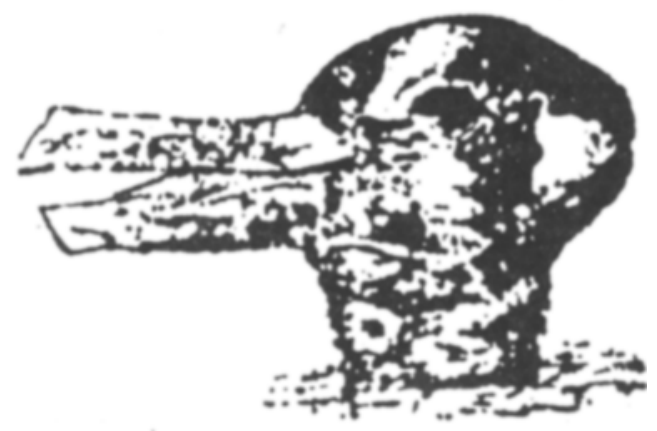

Figure 3. (a) The reversible bird, and (b) the "Rabbiduck." 


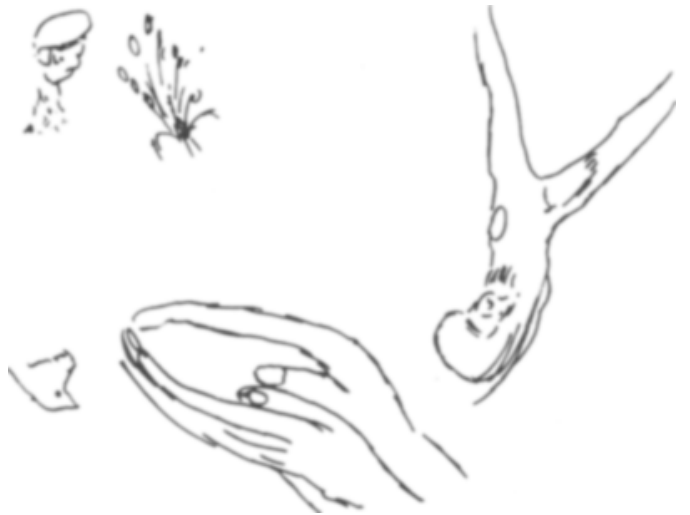

Figure 4. Man with Turban.

could be defended, in line with Chailley's (1976) suggestion that Bosch was giving expression of his conversion to the "true faith," but this must be left for elsewhere.

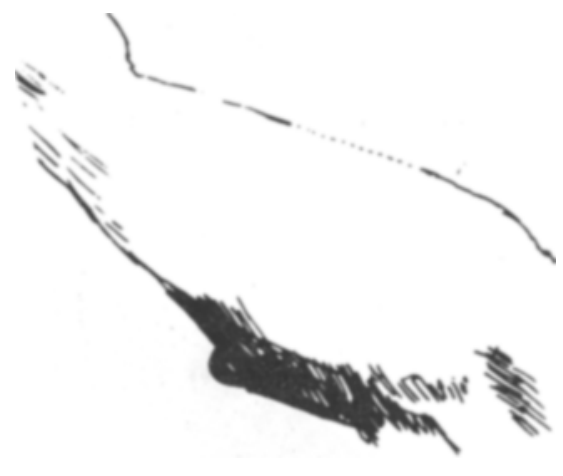

Figure 5. Male anatomy.

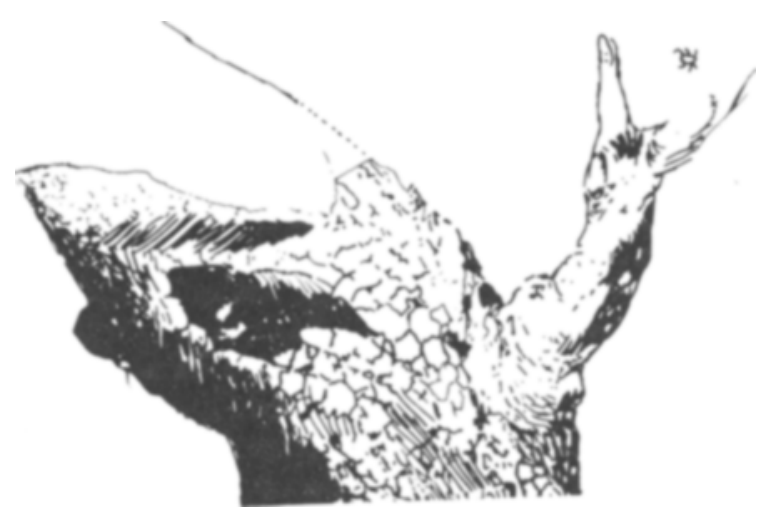

Figure 6. Serpent or lizard with opposing thumb?

\section{REFERENCES}

Bosch, H. (ca. 1500). The owl's nest (drawing). Rotterdam: Museum Boymans - van Beuningen.

Chailley, J. (1976). Jerome Bosch et ses symboles. Brussels: Academie Royale de Belgique Memoires de la Classe des BeauxArts.

Fischer, G. H. (1967). Ambiguous figure treatments in the art of Salvador Dali. Perception \& Psychophysics, 2, 382.

KEY, W. B. (1980). The clam plate orgy. Englewood Cliffs, NJ: Prentice-Hall.

\section{NOTE}

1. Friends to whom we showed the manuscript naturally saw/ found features we had missed. One young lady pointed out that, when turned upside down, the "thigh" in the main branch of the tree can also be seen as a tête de biche, a deer's head. The white spots inside the hole in the tree trunk can be considered the white of one eye; if the figure is considered to be delineated by the owl's wing, which also represents a texture boundary and lies in exactly the right positon to represent such, then the foreshortened head takes on a much more sinister appearance. Taking only the scaly part of the bark as representing one figure, we could easily imagine seeing a snake swallowing the alighting owl (Figure 6).

(Manuscript received December 12, 1983;

revision accepted for publication January 16, 1984.) 